\title{
Extensão e sociedade: diálogos necessários
}

Extension and society: necessary dialogues

\author{
Evonir Albrecht ${ }^{1}$ \\ Antonio Sergio Abrahão Monteiro Bastos ${ }^{2}$
}

\section{RESUMO}

O presente artigo se propõe a fazer uma análise da extensão universitária, suas diferentes definições ao longo da história, seu papel na sociedade e sua importância na tríade Ensino, Pesquisa e Extensão. Para tal, estabelecemos as seguintes questões: Quais as concepções de extensão construídas na legislação brasileira? Como os Objetivos de Desenvolvimento Sustentável (ODS) contribuem para a inserção da extensão nos currículos da graduação? Para responder a estas questões estabelecemos como objetivos: destacar e valorar a extensão como vetor para o diálogo com os diferentes atores da sociedade; e compreender a extensão como um dos pilares da universidade. O trabalho se insere nos moldes da pesquisa qualitativa, de caráter histórico, focando na análise de artigos e documentos que apresentem os diferentes momentos vividos na extensão universitária. Feita a análise, observa-se que a extensão universitária como política pública teve diferentes definições e sempre apresentou um diálogo próximo com a comunidade e as demandas sociais. Neste contexto, passa a configurar como componente curricular obrigatória, denotando sua importância como vetor de aproximação Universidade-Sociedade, neste aspecto, os ODS podem apresentar possibilidades de trabalho, oportunizando a inserção de questões urgentes e necessárias para toda a sociedade.

Palavras-chave: Ensino. Pesquisa. Extensão. Curricularização da extensão. Relação dialógica.

\begin{abstract}
This article proposes to make an analysis of university extension, its different definitions throughout history, its role in society and its importance in the Teaching-Research and Extension triad. To this end, we established the following questions: what are the conceptions of extension built in Brazilian legislation? How do the Sustainable Development Goals (SDG) contribute to the inclusion of Extension in the undergraduate curricular? In order to answer these questions, we established the objective: to highlight and value extension as a vector for dialogue with different actors in society; understand extension as one of the pillars of the university. The work is part of the qualitative research model, of a historical character focusing on the analysis of articles and documents that present the different moments experienced in the university extension. After the analysis, it is observed that university extension as public policy had different definitions and always presented a close dialogue with the community and social demands. In this context, it starts to be configured as a mandatory curricular component, denoting its importance as a vector of University-Society approach, in this aspect, the SDG can present job possibilities, allowing the insertion of urgent and necessary questions for the whole society.

\footnotetext{
${ }^{1}$ Doutor em Ensino de Ciências e Matemática pela Universidade Cruzeiro do Sul, São Paulo, Brasil; professor adjunto A da Universidade Federal do ABC, São Paulo, Brasil (evoniralbrecht@gmail.com).

2 Doutor em Ensino de Ciências e Matemática pela Universidade Cruzeiro do Sul, São Paulo, Brasil; professor da Universidade Nove de Julho, São Paulo, Brasil (a.abrahao@gmail.com).
} 
Keywords: Teaching. Search. Extension. Extension curriculum. Dialogical relationship.

\section{INTRODUÇÃO}

Compreender a extensão como uma política pública ${ }^{3}$ e que dialoga com a sociedade é uma visão um tanto recente, que precisa ser valorada, tendo como uma das principais finalidades aproximar a Universidade da sociedade, como forma de promover e construir políticas alternativas e de relevância social.

Quando buscamos a origem histórica da extensão, temos de retornar ao século XIX, mais precisamente à Inglaterra, como destacado por Nogueira (2001):

A Extensão Universitária surge na Inglaterra, na segunda metade do século XIX, vinculada com a ideia de EDUCAÇÃO CONTINUADA, destinada não apenas às camadas menos favorecidas, mas à população adulta em geral, que não se encontrava na Universidade. [...] Alguns anos depois, registram-se atividades de Extensão nas Universidades americanas, caracterizadas pela prestação de serviços na área rural e também na área urbana (NOGUEIRA, 2001, p. 58, o destaque acompanha original).

Como visto, a ideia de extensão foi construída num panorama de promoção da educação àqueles que não conseguiam acessar o Ensino Superior, caracterizando-se como uma espécie de curso de preparação para a vida que não envolvia, necessariamente, temas vinculados a Academia, não restrito a uma ou outra classe social.

No caso brasileiro, as discussões sobre extensão começaram a ganhar destaque no início do século XX.

As primeiras experiências de extensão no Brasil ocorreram entre 1911 e 1917, na Universidade Livre de São Paulo ${ }^{4}$, por meio de conferências e semanas abertas ao público em que se trabalhavam diversos temas não relacionados às problemáticas sociais e políticas da época. As questões abordadas nessas atividades não estavam focadas nos problemas sociais e econômicos da comunidade (CARBONARI; PEREIRA, 2007, p. 23).

Observa-se que o conceito de extensão inicialmente instituído pouco dialogava com os problemas sociais existentes no Brasil. Não havia preocupação com as questões que afetavam

\footnotetext{
${ }^{3}$ Compreende-se como política pública “o conjunto de programas ou ações governamentais necessárias e suficientes, integradas e articuladas para a provisão de bens ou serviços à sociedade, dotada de recursos orçamentários ou de recursos oriundos de renúncia de receitas e benefícios de natureza financeira e creditícia" (IPEA, 2018, p. 13). Neste contexto, a extensão enquadra-se nesta definição, por sua essência, pela sua definição.

4 A Universidade Livre de São Paulo, inicialmente constituída por cursos ligados a área da saúde, como Medicina, Odontologia e Farmácia, sobreviveu até 1918.
} 
diretamente a sociedade; a extensão possuía um caráter utilitarista apenas, não havendo uma relação de trocas para a sociedade, tão pouco o diálogo com ela. Pouco mais de um século se passou no Brasil e, em 2018, pauta-se a curricularização da extensão, que passará a fazer parte dos diferentes currículos dos cursos de graduação brasileira.

Neste contexto, emergem as questões norteadoras deste trabalho que são: Quais as concepções de extensão construídas na legislação brasileira? Como os Objetivos de Desenvolvimento Sustentável (ODS) contribuem para a inserção da extensão nos currículos da graduação? Para respondê-las, estabelecemos como objetivos: destacar e valorar a extensão como vetor para o diálogo com os diferentes atores da sociedade; e compreender a extensão como um dos pilares da Universidade.

Por fim, para justificar a relevância deste trabalho, ressalta-se que as ações de extensão universitária tiveram importância enorme ao longo dos anos, atuando na aproximação da Universidade com sociedade e promovendo diferentes atividades com o intuito de estabelecer um canal direto de comunicação entre essas instâncias. A extensão estabelece e utiliza desta relação dialógica para propor temáticas latentes à sociedade.

Neste trabalho, por relação dialógica entende-se o desenvolvimento ou a construção de relações entre a Universidade e os diferentes atores sociais para a construção de uma via de mão-dupla nas diferentes trocas de saberes possíveis e superação do discurso da hegemonia acadêmica historicamente presente (FORPROEX, 2001) e, muitas vezes, tão distante das reais necessidades da nossa sociedade.

\section{ASPECTOS METODOLÓGICOS}

Os moldes da pesquisa inserem-se na pesquisa do tipo qualitativa. Para Bicudo (2005), pesquisas desse tipo significam "ter uma interrogação e andar em torno dela em todos os sentidos". Desta forma, a preocupação para a realização desta pesquisa não está relacionada com a representatividade, mas sim com o aprofundamento dado na ênfase da compreensão das questões historicamente ligadas às políticas de extensão até a regulamentação sobre sua obrigatoriedade na grade curricular dos cursos de graduação na proporção de $10 \%$.

Neste trabalho, procederemos a análise de artigos e diferentes documentos. A intenção de selecionar a legislação disponível é justificada pelo fato de serem documentos oficiais. Sobre 
documentos oficiais, Marconi e Lakatos (2005, p. 180) consideram que "constituem geralmente a fonte mais fidedigna de dados". Além disso, esses documentos são públicos e válidos. É importante destacar que todos estão disponíveis na internet, em sites de fácil acesso.

Os documentos utilizados para análise no presente trabalho foram: I Encontro de Pró-Reitores de Extensão das Universidades Públicas Brasileiras. Conceito de Extensão, institucionalização e financiamento (FORPROEX, 1987).Constituição de 1988 (BRASIL, 1988); Plano Nacional de Extensão Universitária (PNExt., 2000; 2001); Lei de Diretrizes e Bases da Educação Nacional (LDB 9394/1996) (BRASIL, 1996); Resolução nº 7, de 18 de dezembro de 2018, que Estabelece as Diretrizes para a Extensão nas Educação Superior Brasileira (BRASIL, 2019).

Após a identificação, impressão e coleta desses documentos, realizou-se uma análise prévia na tentativa de averiguar a autenticidade documental. Foi verificado que os documentos são autênticos; os documentos disponibilizados nos sites são cópias digitalizadas dos oficiais ou com autenticação digital e aprovados pelas referidos órgãos.

O intuito deste artigo é realizar um mapeamento da legislação, dos diferentes momentos políticos no Brasil em relação à implementação das políticas de extensão nas Instituições Públicas de Ensino Superior e possibilidades para auxiliar na inserção da extensão nos cursos de graduação.

A análise levou em consideração inicialmente a importância de cada documento na instituição da extensão universitária como política pública e seus diferentes desdobramentos ao longo da história, com o intuito de elaborar uma análise da situação da extensão até os dias atuais, seus desdobramentos e sua inserção como componente curricular.

\section{REFERENCIAL TEÓRICO}

A extensão universitária tem-se desenvolvido em diferentes vertentes ao longo da história. Inicialmente possuía um caráter assistencialista, ou seja, tentando cumprir um papel distante da relação dialógica esperada, mas, atuando num formato propositivo de ações pontuais e desconexas da realidade da sociedade, mais num caráter obrigatório do que propositivo, constituindo-se em sua maioria de cursos de curta duração (MEDEIROS, 2017). Sua 
compreensão passa por aspectos históricos relacionados e suas primeiras definições. Como ponto de partida, podemos ressaltar as ideias iniciais sobre o tema em questão, originárias em meados do século XIX na Inglaterra, para a América. As ações de extensão já ocorriam no Brasil, mas, apenas em 1911, é instituída a primeira Lei Orgânica do Ensino Superior (BRASIL, 1911), “dando autonomia curricular e pedagógica às Universidades” (ALMEIDA, 2015, p. 60).

O ano de 1918 foi de grande relevância. Nesse ano, um documento, conhecido como Manisfesto de Córdoba,

apresenta para a extensão a função de vincular a Universidade à Sociedade. Este Manifesto passou a influenciar efetivamente os discursos oficiais e as propostas dos segmentos componentes da estrutura universitária na questão da missão social da Universidade. Desta forma, abriu espaços que possibilitaram uma Universidade mais crítica, com uma visão de instituição que mantivesse um compromisso com a Sociedade, na direção não só de seu desenvolvimento, mas também da sua transformação. (ALMEIDA, 2015, p. $60)$.

A proposta de Córdoba, celebrada até os dias atuais, viria a alterar os rumos da compreensão da extensão e de suas funções. Com o passar dos anos, outras discussões fomentaram alterações nas definições e estas foram aprimoradas, em 1931.

O "Estatuto da Universidade Brasileira" (Decreto Federal no 19.851 de 11 de abril de 1931), delineou como atividades de extensão não só a realização de cursos e conferências objetivando a difusão de conhecimentos "úteis a vida individual e coletiva", mas também a "apresentação de soluções para os compromissos e a propagação de ideias e princípios de interesse naciona". (CARBONARI; PEREIRA, 2007, p. 23).

Começa a emergir a necessidade de repensar a extensão universitária como política pública de aproximação e preocupação com as demandas da sociedade. A aproximação da universidade com a sociedade passa a estreitar-se. Na década de 1960, em virtude das diferentes mobilizações sociais, a extensão universitária passa do papel de divulgadora do conhecimento científico para um papel mais pró-ativo, focando em atividades que possibilitassem a transformação social. Esta visão é interrompida com a Reforma Universitária de 1968, que orientada pelos princípios da Lei da Segurança Nacional, "rompe com a concepção da extensão como espaço de diálogo com a comunidade, restringindo as ações das IES e impedindo-as do exercício de autonomia" (CARBONARI; PEREIRA, 2007, p. 23-24). A reforma define que o ensino superior deve ser pautado pela indissociabilidade entre ensino e 
pesquisa, afetando diretamente as construções acerca de extensão universitária vigentes na época.

Em 1975, no plano de trabalho desenvolvido pelo MEC, uma nova definição emerge e a extensão passa a ser compreendida como forma de atendimento pelas universidades às outras instituições e população, recebendo demandas e retornos que passam a ser considerados subsídios para o ensino e pesquisa (CARBONARI; PEREIRA, 2007).

O Conselho dos Reitores das Universidades Brasileiras (CRUB) define, em consonância ao plano de trabalho do MEC, que as atividades de extensão seriam pautadas segundo três ideias principais: "oferta de serviços à população, fornecimento de material de trabalho à universidade e a integração dessas duas ênfases (FEHLBERG; SILVA; VALLE, 2014, p. 2)”. Percebe-se aí, um retorno e reabertura ao diálogo com as questões sociais, tal aspecto seria fortalecido a partir da década de 1980 com o ressurgimento de diferentes movimentos sociais. Neste contexto, as universidades reacendem as discussões com a sociedade e passam a desenvolver práticas extensionistas com ênfase nos direitos humanos, mas, os aspectos assistenciais ainda estão presentes.

No Brasil, diante da necessidade de um órgão representativo que possibilitasse o diálogo para a construção de uma política de extensão, em 1987, é instituído o Fórum Nacional de PróReitores de Extensão das Universidades Públicas Brasileiras (FORPROEX). Este Fórum "é uma entidade voltada para a articulação e definição de políticas acadêmicas de extensão, comprometida com a transformação social para o pleno exercício da cidadania e o fortalecimento da democracia" (FORPROEX, 2016). De acordo com Rodrigues (2015, p. 392), o FORPROEX

foi criado e implantado em 6 de novembro de 1987, durante o I Encontro Nacional de Pró-Reitores de Extensão das Universidades Públicas, ocorrido na Universidade de Brasília - UnB, tendo como perspectiva a compreensão de extensão indicada anteriormente. Em reunião ocorrida em 26 de novembro de 2010, na Universidade Federal do ABC, no estado de São Paulo, o Fórum aprovou sua proposta de regimento, por meio do qual definiu, de modo mais preciso, sua estrutura e funcionamento.

É evidente a preocupação do FORPROEX com as políticas sociais latentes na sociedade e que demandam de atitudes para aproximar a Universidade pública da sociedade. São membros do FORPROEX os Pró-reitores de Extensão de todas as Instituições Públicas Brasileiras de 
Ensino Superior ou órgão correspondente, tendo direito de voz e voto. São objetivos do Fórum:

I. Propor políticas e diretrizes básicas que permitam a institucionalização, a articulação e o fortalecimento de ações comuns das Pró-Reitorias de Extensão e órgãos congêneres das Instituições de Ensino Superior Públicas Brasileiras; II. Manter articulação permanente com representações dos Dirigentes de Instituições de Educação Superior, visando encaminhamento das questões referentes às proposições do Fórum de Pró-Reitores de Extensão das Universidades Públicas Brasileiras; III. Manter articulação permanente com os demais Fóruns de Pró-Reitores, com o objetivo de desenvolver ações conjuntas que visem a real integração da prática acadêmica; IV. Manter articulação permanente com instituições da sociedade civil, do setor produtivo e dos poderes constituídos, com vistas à constante ampliação da inserção social das Universidades Públicas; V. Incentivar o desenvolvimento da informação, avaliação, gestão e divulgação das ações de extensão realizadas pelas Instituições de Ensino Superior Públicas Brasileiras. (FORPROEX, 2016).

O FORPROEX teve um papel importante nas novas definições de extensão universitária que passaram a ser construídas. A Constituição de 1988, em seu artigo 207, já apresentava que "As universidades gozam de autonomia didático-científica, administrativa e de gestão financeira e patrimonial, e obedecerão ao princípio de indissociabilidade entre ensino, pesquisa e extensão (BRASIL, 1988, grifos nossos)"'. A extensão universitária se faz presente na promulgação da Constituição Cidadã.

Em 1996, outro marco importante para a Educação Brasileira: a promulgação da Nova Lei de Diretrizes de Bases da Educação Nacional (LDB) (BRASIL, 1996). A Lei nº 9.394/1996 passa a fomentar outras Leis e Planos que viriam a ser propostos. Carbonari e Pereira (2007, p. 24), destacam que:

A Lei de Diretrizes e Bases da Educação Nacional (LDBEN - Lei 9.394/96) e o Plano Nacional de Extensão (1999-2001) retomam a questão de indissociabilidade das atividades de ensino, extensão e pesquisa, fazendo com que as IES repensem sua função social colocando em pauta a natureza de suas atividades-fim.

$\mathrm{Na}$ atual LDB, o artigo $43^{\circ}$ versa sobre a finalidade da Educação Superior. Em seu parágrafo VII, é ressaltado que a Educação Superior deve "promover a extensão, aberta à participação da população, visando à difusão das conquistas e benefícios resultantes da criação cultural e da pesquisa científica e tecnológica geradas na instituição" (BRASIL, 1996). Pode-se compreender por esse artigo, que é ensejado que a extensão universitária seja incorporada ao trabalho do docente, como parte da tríade Ensino, Pesquisa e Extensão, definida como indissociável. 
Em consonância ao que foi regulamentado pela LDB (BRASIL, 1996), o FORPROEX, apresenta-se como importante articulador nas diferentes esferas. Para Rodrigues (2015, p. 393),

A partir de 1996, esse Fórum seguiu em busca de interlocução com os diferentes ministérios e passou a produzir documentos de referência para consolidação do processo de institucionalização da Extensão, parcialmente apoiada pelo MEC, tendo como marco o lançamento da proposta do Plano Nacional de Extensão - PNExt, formulada pelo Forproex e concebida na perspectiva do fortalecimento da extensão universitária. Nessa proposta do Forproex, estavam definidas as diretrizes para a Extensão universitária que visavam, por meio de atividades extensionistas, possibilitar a efetivação de políticas públicas e o exercício da cidadania a partir da sua implementação.

Nos anos de 2000 e 2001, ocorre a atualização do FORPROEX para o Plano Nacional de Extensão (PNExt), que passa a definir as diretrizes da extensão universitária, tendo por base quatro pilares:

- Impacto e transformação: estabelecimento de uma relação entre a Universidade e outros setores da Sociedade, com vistas a uma atuação transformadora, voltada para os interesses e necessidades da maioria da população e implementadora de desenvolvimento regional e de políticas públicas. Essa diretriz consolida a orientação para cada ação da Extensão universitária: frente à complexidade e a diversidade da realidade, é necessário eleger as questões mais prioritárias, com abrangência suficiente para uma atuação que colabore efetivamente para a mudança social. Definida a questão, é preciso estudá-la em todos seus detalhes, formular soluções, declarar o compromisso pessoal e institucional pela mudança, e atuar.

- Interação dialógica: desenvolvimento de relações entre universidade e setores sociais marcadas pelo diálogo, pela ação de mão-dupla, de troca de saberes, de superação do discurso da hegemonia acadêmica - que ainda marca uma concepção ultrapassada de extensão: estender à sociedade o conhecimento acumulado pela universidade - para uma aliança com movimentos sociais de superação de desigualdades e de exclusão.

- Interdisciplinaridade: caracterizada pela interação de modelos e conceitos complementares, de material analítico e de metodologias, buscando consistência teórica e operacional que estruture o trabalho dos atores do processo social e que conduza à interinstitucionalidade, construída na interação e inter-relação de organizações, profissionais e pessoas.

- Indissociabilidade ensino - pesquisa - extensão: reafirmando a extensão como processo acadêmico - justificando-lhe o adjetivo "universitária" -, em que toda ação de extensão deverá estar vinculada ao processo de formação de pessoas e de geração de conhecimento, tendo o aluno como protagonista de sua formação técnica para obtenção de competências necessárias à atuação profissional, e de sua formação cidadã - reconhecerse agente da garantia de direitos e deveres, assumindo uma visão transformadora e um compromisso. (PNEXT, 2000/2001, p. 18-19). 
Essas quatro linhas subsidiaram a construção de políticas em diferentes instituições de Ensino Superior, como o documento da Universidade Federal do ABC (UFABC), a saber, a Resolução do CEC (Comitê de Extensão e Cultura) n ${ }^{\circ}$ 7, de 18 de abril de 2017, que em seu parágrafo primeiro propõe:

Art. $1^{\circ}$ Definir as atividades de Extensão Universitária como aquelas que promovem de maneira direta a interação transformadora e dialógica entre Universidade e sociedade, por meio de processos interdisciplinares, educativos, culturais, científicos e/ou políticos, sob o princípio constitucional da indissociabilidade entre a própria extensão, o ensino e a pesquisa. (UFABC, 2017, p. 27).

A definição de extensão apresentada nesta resolução está em acordo ao que é previsto no PNExt e nas políticas nacionais de extensão. Tais aspectos subsidiaram diferentes discussões em diferentes esferas. Mais recentemente, em 18 de dezembro de 2018, o Conselho Nacional de Educação (CNE) aprova a Resolução n ${ }^{0}$ 7, que "Estabelece as Diretrizes para a Extensão na Educação Superior Brasileira e regimenta o disposto na meta 12.7 da Lei n ${ }^{\circ}$ 13.005/2014, que aprova o Plano Nacional de Educação - PNE-2014-2024 e dá outras providencias" (BRASIL, 2018, p. 1).

Esta Resolução apresenta as orientações, considerações e deliberações para a inserção das atividades de extensão como curriculares, em atendimento à meta 12.7, do PNE (2014-2014). $\mathrm{Na}$ curricularização da extensão, o protagonista é o aluno, sendo três anos o prazo para a implementação nos currículos dos cursos de graduação. Outrossim, a Resolução define que as “atividades extensionistas, segundo sua caracterização nos projetos políticos pedagógicos dos cursos, se inserem nas seguintes modalidades: I - programas; II - projetos; III - cursos e oficinas; IV - eventos; V - prestação de serviços (BRASIL, 2018, p. 3)" e, ainda, "as atividades de extensão podem ser realizadas com parceria entre instituições de ensino superior, de modo que estimule a mobilidade interinstitucional de estudantes e docentes (BRASIL, 2018, p. 4)".

Por se tratar de uma resolução recente, ainda há muitas questões para serem sistematizadas, dentre as quais: Como transformar $10 \%$ da grade curricular de cada curso em atividades extensionistas, vista a diversidade de cursos. Muitos docentes não oferecem cursos de extensão, mesmo que os concursos os prevejam como atividade docente. Como exemplo, podemos citar o Edital $n^{\circ}$ 96, de 8 de agosto de 2013 da UFABC, que versa sobre as condições gerais de Concurso para provimento de cargo efetivo de Professor Adjunto A Nível I, da carreira do Magistério Superior, no qual, em seu item 2. Regime de Trabalho 
explicita: "2.1. O regime de trabalho, de acordo com o Art. 20, da Lei no 12.772/2012, será o de 40 (quarenta) horas semanais de trabalho, em tempo integral, com dedicação exclusiva às atividades de ensino, pesquisa, extensão e gestão institucional” (UFABC, 2013, p. 1, grifo nosso).

\section{RESULTADOS}

A análise dos dados se caracteriza por um momento importante, momento de análise e interpretação dos dados, bem como cruzamento de informações obtidas ao longo de todo o percurso da pesquisa. Neste contexto, retomamos as questões inicialmente propostas para discussão, bem como os objetivos para observar se foram ou não atingidos.

Nos documentos analisados, no tocante a primeira questão colocada neste artigo - Quais as concepções de extensão construídas na legislação brasileira? -, observou-se que a extensão universitária passou por diferentes momentos históricos, que compreendeu desde aspectos mais utilitaristas até a uma visão social e próxima às demandas da sociedade. Passou por um momento de silêncio na época da Ditadura e, a partir da década de 1980, com a emergência de movimentos sociais, mostrou-se alinhada às questões de relevância social que aproximam a Universidade da sociedade e ressaltam a indissociabilidade entre Ensino, Pesquisa e Extensão, conquistada na Constituição Federal de 1988.

A instituição da extensão universitária nas diversas universidades do país se deu de diferentes formas. Várias discussões emergiram desta demanda: algumas instituições focam pela gratuidade de seus projetos, programas ou cursos; outras focam na taxação, e aí denotam um caráter assistencialista. Tal duplicidade de entendimento é justificada pelo próprio histórico da compreensão da definição da extensão universitária.

Até a proposta de curricularização da extensão, vários movimentos ocorreram. Destaca-se a criação, em 1987, do FORPROEX, que fortaleceu e oportunizou discussões importantes, denotando e ressaltando a extensão universitária, que, em virtude da diferente tipologia na sua compreensão, mostra-se importante para manutenção do tripé Ensino, Pesquisa e Extensão. O Quadro 1 busca sintetizar os momentos históricos apresentados ao longo deste texto. 
Quadro 1 - Histórico da extensão universitária

\begin{tabular}{|c|c|}
\hline Período & Extensão \\
\hline $\begin{array}{l}\text { Meados do } \\
\text { Século XIX }\end{array}$ & Primeiras ações de extensão na Inglaterra. \\
\hline 1911/1917 & $\begin{array}{l}\text { Registro de primeiras ações de extensão no Brasil na Universidade Livre de } \\
\text { São Paulo. }\end{array}$ \\
\hline 1931 & Novo Estatuto da Universidade Brasileira. \\
\hline 1960 & Papel Pró-ativo da extensão. \\
\hline 1968 & Reforma Universitária (indissociabilidade entre ensino e pesquisa). \\
\hline 1975 & Nova definição de extensão \\
\hline 1980 & $\begin{array}{l}\text { Retorno e reabertura ao diálogo com as questões sociais da e para a } \\
\text { sociedade. }\end{array}$ \\
\hline 1987 & Criação do FORPROEX, destacando a importância da extensão universitária. \\
\hline 1988 & $\begin{array}{l}\text { Constituição Brasileira, destaque para o Art. } 207 \text { - Indissociabilidade entre } \\
\text { ensino-pesquisa e extensão. }\end{array}$ \\
\hline 1996 & $\begin{array}{l}\text { Lei de Diretrizes e Bases da Educação (LDB) - Reforço ao tripé universitário } \\
\text { - ensino-pesquisa-extensão }\end{array}$ \\
\hline 2000/2001 & $\begin{array}{l}\text { Plano Nacional de Extensão - Diretrizes da extensão pautada sob quatro } \\
\text { pilares: Impacto e transformação; Interação dialógica; Interdisciplinaridade; } \\
\text { Indissociabilidade Ensino-Pesquisa-Extensão. }\end{array}$ \\
\hline 2018 & Resolução n $^{\circ}$, de 18 de dezembro de 2018 - Curricularização da extensão. \\
\hline
\end{tabular}

Fonte: Os autores (2020).

O Quadro 1 sintetiza a extensão ao longo da história, apresentando seus primórdios na Inglaterra e que, segundo Nogueira (2001), alguns anos mais tarde as ações de extensão seriam observadas em universidades americanas, relacionadas a prestação de serviços na zona rural e urbana. Esta síntese apresenta também a evolução da compreensão da extensão no Brasil, bem como das diferentes regulamentações até o ano de 2018, ano em que pela Resolução $n^{\circ} 7$, normatiza sua inserção como componente curricular obrigatória, num total de $10 \%$ da grade curricular de cada curso de graduação. Tal aspecto vem ressaltar a importância do tripé Ensino-Pesquisa-Extensão, demonstrando a relevância destas atividades para a 
Universidade. A Extensão passa também a ser vista ao longo dos diferentes períodos um terreno fértil para pesquisas nas diferentes áreas.

Porém, até a presente data não há ainda uma definição de como cada universidade fará para contemplar a resolução. Alguns acenos que podemos observar são: a transformação de disciplinas de graduação em ações de extensão, dirigidos para o público externo, não acadêmico e que necessita de algum olhar específico em consonância às diferentes políticas públicas. Ressalta-se que, já em 1987, em sua criação, o $\operatorname{FORPROEX~(1987,~p.~11)~define~}$ extensão universitária como

o processo educativo, cultural e científico que articula o ensino e a pesquisa de forma indissociável e viabiliza a relação transformadora entre a universidade e a sociedade.

A extensão é uma via de mão-dupla, com trânsito assegurado à comunidade acadêmica, que encontrará, na sociedade, a oportunidade da elaboração da práxis de um conhecimento acadêmico. No retorno à universidade, docentes e discentes trarão um aprendizado que, submetido à reflexão teórica, será acrescido àquele conhecimento. Este fluxo, que estabelece a troca de saberes sistematizados/acadêmico e popular, terá como consequência: a produção de conhecimento resultante do confronto com a realidade brasileira e regional; e a democratização do conhecimento acadêmico e a participação efetiva da comunidade na atuação da universidade.

Além de instrumentalizadora deste processo dialético de teoria/prática, a extensão é um trabalho interdisciplinar que favorece a visão integrada do social.

Observa-se que há uma preocupação significativa com os problemas de ordem social e com a relação dialógica que se espera entre as esferas da Universidade e sociedade, que possam retroalimentar-se. Em relação aos objetivos elaborados para resolver as questões, ressaltamos que o primeiro possibilitou a visualização de diferentes momentos vividos pela extensão universitária, frutos de diferentes momentos políticos que impactaram fortemente em sua construção e consolidação como política pública.

Neste contexto, a extensão é reconhecida como importante vetor para o diálogo e proposição de ações para diferentes segmentos da sociedade. Atuando como canal de aproximação e oportunização para criação de cursos para formação, aprimoramento, dentre outros, e que consigam, por meio do diálogo, trazer demandas latentes na sociedade para dentro da Universidade, que aproximem e prezem pela indissociabilidade ensino-pesquisa-extensão. 
Sobre o segundo questionamento a ser respondido neste trabalho - Como os ODS contribuem para a inserção da extensão nos currículos da graduação? - o documento que define as diretrizes para a extensão na educação superior brasileira (Resolução $n^{\circ} 7 / 2018$ ) tem gerado diferentes entendimentos e fomentado muita discussão em âmbito nacional, por meio do FORPROEX Nacional e Congresso Brasileiro de Extensão Universitária (CBEU), e regional, por meio do FORPROEX Sudeste.

Uma das possibilidades pode ser via inserção dos ODS no cerne das ações, visto seu caráter extremamente extensionista. Em setembro de 2015, os 193 países membros das Organização pelas Nações Unidas (ONU) adotaram uma nova política global, a Agenda 2030 para o desenvolvimento sustentável, caracterizada como "um plano de ação para as pessoas, para o planeta e para a prosperidade (ONU, 2015, p. 1).

A Agenda prioriza vários itens, dentre eles a erradicação da pobreza extrema, um dos pilares para o desenvolvimento sustentável. Ressalta-se, ainda, que muitas universidades utilizam diferentes sistemas para inserção de ações de extensão, como o Sistema Integrado de Gestão (SIG), o Sistema Integrado de Gestão Acadêmico (SIGA), dentre outros. Neste caso, o SIGA, já prevê, no momento da inserção de uma ação extensionista, o link direto com os ODS e, nesta perspectiva, tal ação pode ser estimulada.

O documento dos ODS possui 49 páginas e apresenta 17 objetivos com 169 metas. Estas necessitam de uma ação conjunta, agregando diferentes níveis de governo, organizações, empresas e sociedade, em diferentes áreas, sendo que todas elas apresentam relação direta com o papel da extensão universitária.

Os 17 Objetivos de Desenvolvimento Sustentável e 169 metas que estamos anunciando hoje demonstram a escala e a ambição desta nova Agenda universal. Eles se constroem sobre o legado dos Objetivos de Desenvolvimento do Milênio e concluirão o que estes não conseguiram alcançar. Eles buscam concretizar os direitos humanos de todos e alcançar a igualdade de gênero e o empoderamento das mulheres e meninas. Eles são integrados e indivisíveis, e equilibram as três dimensões do desenvolvimento sustentável: a econômica, a social e a ambiental. (ONU, 2015, p. 01).

Partindo desta premissa e tendo por base o que se apresenta nesta proposta de Agenda, observa-se o quão dialógica ela é. As questões perpassam a sociedade de modo geral, indo ao encontro das perspectivas e definições acerca do que é compreendido como extensão. Os ODS foram construídos tendo por base os Objetivos de Desenvolvimento do Milênio (ODM), que estiveram em vigor de 2000 a 2015 . Tratam de temas globais, mas que se relacionam às 
diferentes realidades, focando no desenvolvimento sustentável, justo e inclusivo (ONU, 2015). Na Figura 1, estão apresentados os ODS.

Figura 1 - Objetivos de Desenvolvimento Sustentável

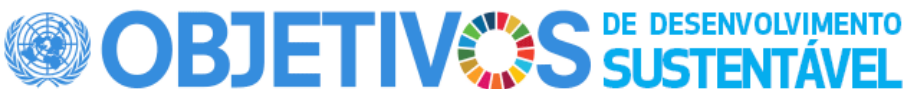
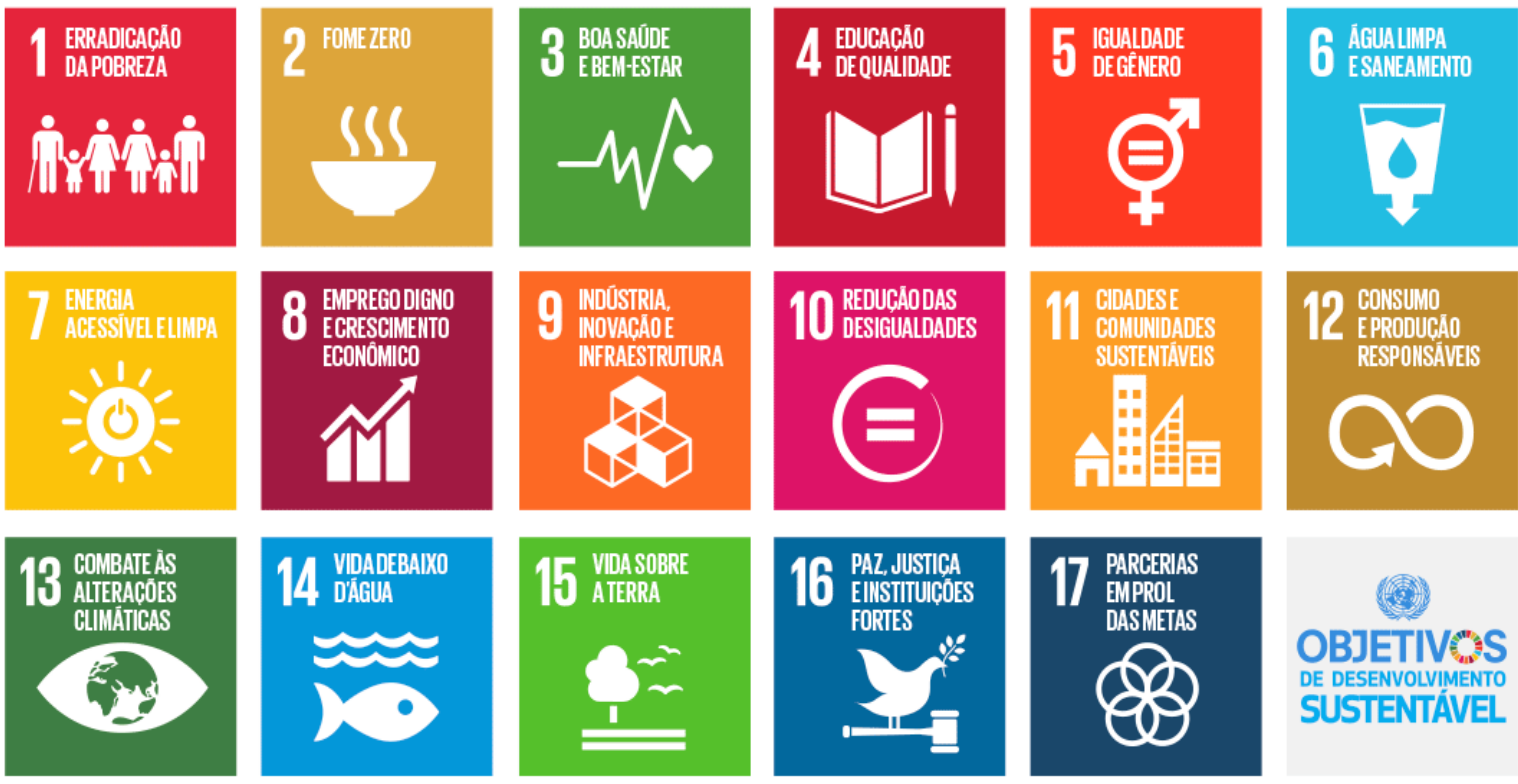

OBJETIVOS

DE DESENVOLVIMENTO SUSTENTÁVEL

Fonte: http://www.itamaraty.gov.br/pt-BR/politica-externa/desenvolvimento-sustentavel-e-meioambiente/134-objetivos-de-desenvolvimento-sustentavel-ods

Todas as temáticas apresentadas carecem de trabalho na e com a sociedade, como o empoderamento das mulheres e meninas que recebe especial atenção no documento, sendo apenas uma das tantas temáticas recomendadas. Outro ponto importante do documento é o respeito aos direitos humanos e às recomendações enfatizadas no tocante ao seu alcance e sua universalização.

Esta agenda ambiciosa estabelece um teto de 15 anos para concretização dos ODS, cujas áreas de abrangência são: pessoas, planeta, prosperidade, paz e parceria (ONU, 2015). Cada uma das áreas de ação do documento está diretamente relacionada ao que concerne a extensão. Tal aspecto fortalece e corporifica a importância da interação dialógica com a sociedade, bem como fortalece o tripé ensino-pesquisa-extensão. 


\section{CONSIDERAÇÕES FINAIS}

Observa-se que a extensão desempenhou, ao longo da história, um papel importante na sociedade, passando de um caráter utilitarista, assistencialista até a forma como hoje se apresenta: importante política pública, canal direto com a sociedade. A importância da extensão como canal direto de diálogo com a sociedade se fortalece com a criação do FORPROEX, em 1987, e se consolida com a Constituição de 1988, se corporificando como um dos importantes tripés da Universidade.

Desconstruir muros, aproximar a Universidade da sociedade e possibilitar que a sociedade se empodere da Universidade é substancial para que a extensão se fortaleça cada vez mais e torne a Universidade de fato universal. Nesta perspectiva, ao trazer a sociedade para dentro da Universidade, oportuniza-se o diálogo, a desconstrução das certezas e dogmas por tanto tempo tidos como substanciais para manutenção dos modelos existentes e, com certeza, ao partilhar o conhecimento, constrói-se uma sociedade inclusa na Universidade, incluindo a Universidade na sociedade.

A curricularização da extensão pode propiciar essa aproximação. O trabalho com os ODS pode ser um caminho possível, de tantos que há, pelo seu profundo caráter extensionista, bem como na forte relação dialógica com a sociedade. Neste contexto, a extensão passa a compor o tripé ensino-pesquisa-extensão, corporificando-se como um dos pilares da Universidade e sendo um vetor de diálogo, atuando de forma transversal, como termômetro junto à sociedade para construção de políticas aliadas às necessidades da sociedade vigente. Os ODS não são a solução definitiva para estas discussões, mas, podem apontar caminhos para visualizar políticas extensionistas profundas que a sociedade carece.

Outrossim, ressalta-se que mesmo após todos os avanços em termos conceituais, de definição, de ação e de compreensão ainda há um longo caminho a percorrer para a extensão estabelecer-se de fato como componente curricular da graduação, fato este que deve gerar várias pesquisas que apontarão possibilidades viáveis e reais de tornar o aluno protagonista de seu próprio aprendizado, aproximando a universidade da sociedade, para de fato construir uma via de mão dupla, que se retroalimentem para construção de novas possibilidades. 


\section{REFERÊNCIAS}

ALMEIDA, L. A. P. de. Extensão universitária no Brasil: processos de aprendizagem a partir da experiência e do sentido. Diversités Recherches et Terrains, Limoges, n. 7., 2015. Disponível em: https://www.unilim.fr/dire/692. Acesso em: 20 fev. 2020.

BICUDO, M. A. V. Pesquisa qualitativa: significados e a razão que a sustenta. Pesquisa qualitativa: SE/PQ, v. 1., n. 1, 2001. Disponível em: https://editora.sepq.org.br/index.php/rpq/article/view/7. Acesso em: 10 mar. 2020.

BRASIL. Constituição (1988). Constituição da República Federativa do Brasil. Brasília, DF: Senado Federal, 1988.

BRASIL. Decreto n ${ }^{\circ}$ 8.659, de 5 de abril de 1911. Aprova a Lei Orgânica do Ensino Superior e do Fundamental na República. Disponível em: http://www.histedbr.fe.unicamp.br/navegando/fontes_escritas/4_1a_Republica/decreto\%2086 59\%20-\%201911\%201ei\%20org\%E2nica\%20rivad\%E1via\%20correia.htm. Acesso em: 10 mar. 2020.

BRASIL. Ministério da Educação. Conselho Nacional de Educação. Resolução nº 7, de 18 de dezembro de 2018. Estabelece as Diretrizes para a Extensão na Educação Superior Brasileira e regimenta o disposto na Meta 12.7 da Lei $\mathrm{n}^{\circ}$ 13.005/2014, que aprova o Plano Nacional de Educação - PNE 2014-2024 e dá outras providências. Disponível em:? http://portal.mec.gov.br/index.php?option=com_docman\&view=download\&alias=104251 rces007-18\&category_slug=dezembro-2018-pdf\&Itemid=30192. Acesso em: 15 mar. 2020.

BRASIL. Ministério da Educação. Lei de Diretrizes e Bases da Educação Nacional. Lei n ${ }^{o}$ 9.394, de 20 de dezembro de 1996. Estabelece as diretrizes e bases da Educação Nacional. Brasília, DF, 1996.

CARBONARI, M. E. E.; PEREIRA, A. C. A extensão universitária no Brasil, do assistencialismo à sustentabilidade. Revista de Educação, Londrina, v. 10, n. 10, 2007. Disponível em: http://revista.pgsskroton.com.br/index.php/educ/article/view/2133/2030. Acesso em: 30 abr. 2019.

CELLARD, A. A análise documental. In: POUPART, J. et al. A pesquisa qualitativa: enfoques epistemológicos e metodológicos. Petrópolis, RJ: Vozes, 2008.

FEHLBERG, J.; SILVA, M. C.; VALLE, P. C. Eu, meus filhos e nossa escola: pensando a extensão universitária na escola regular. Psicologia em Foco, Frederico Westphalen, v. 4, n.17, 2014.

FORPROEX - FÓRUM DE PRÓ-REITORES DAS INSTITUIÇÕES PÚBLICAS DE EDUCAÇÃO SUPERIOR BRASILEIRAS. O Forproex. In: Rede Nacional de Extensão RENEX. 2016.2 Disponível em: https://www.ufmg.br/proex/renex/index.php/apresentacao/forproex-e-renex. Acesso em: 8 maio 2019. 
FORPROEX - FÓRUM DE PRÓ-REITORES DE EXTENSÃO DAS UNIVERSIDADES PÚBLICAS BRASILEIRAS. Conceito de extensão, institucionalização e financiamento. 1987. Disponível em: https://www.ufmg.br/proex/renex/images/documentos/1987-IEncontro-Nacional-do-FORPROEX.pdf. Acesso em: 5 maio 2019.

IPEA - INSTITUTO DE PESQUISAS ECONÔMICAS E APLICADAS. Avaliação de políticas públicas: guia prático de análise. Brasília: IPEA, 2018.

MARCONI, M. A.; LAKATOS, E. M. Fundamentos de metodologia científica. 6. ed. São Paulo: Atlas, 2005.

MEDEIROS, M. M. de. A extensão universitária no Brasil: um percurso histórico. Barbaquá, Dourados, v. 1, n. 1, p. 09-16, jan./jun. 2017. Disponível em: https://periodicosonline.uems.br/index.php/barbaqua/article/view/1447. Acesso em: 15 mar. 2020.

NOGUEIRA, M. D. P. Extensão universitária no Brasil: uma revisão conceitual. In: FARIA, D. S. (org.). Construção conceitual da extensão universitária na América Latina. Brasília: Editora da UnB, 2001.

ONU - Organização das Nações Unidas. Transformando nosso mundo: a agenda 2030 para o desenvolvimento sustentável. Disponível em: https://nacoesunidas.org/wpcontent/uploads/2015/10/agenda2030-pt-br.pdf. Acesso em: 20 jan. 2020.

PNEXT - PLANO NACIONAL DE EXTENSÃO UNIVERSITÁRIA 2011-2020. Disponível em: $\quad$ http://pdi.ufabc.edu.br/wp-content/uploads/2011/09/Plano-Nacional-deExtens\%C3\%A3o-Universit\%C3\%A1ria-2011-2020.pdf. Acesso em: 18 abr. 2020.

RODRIGUES, V. M. O fórum de pró-reitores de extensão e sua contribuição no debate sobre a extensão universitária. Revista Educação e Políticas em Debate, Uberlândia, v. 4, n .2, ago./dez. 2015.2 Disponível em: http://www.seer.ufu.br/index.php/revistaeducaopoliticas/article/view/34562. Acesso em: 15 abr. 2020.

UFABC - UNIVERSIDADE FEDERAL DO ABC. Edital $n^{\circ}$ 96, de 8 de agosto de 2013. Condições gerais de Concurso para provimento de cargo efetivo de Professor Adjunto A Nível I, da carreira do Magistério Superior. Disponível em: http://www.ufabc.edu.br/images/concursos_docentes/edital-96-2013-com-alteracoes.pdf. Acesso em: $1^{\circ}$ maio 2020.

UFABC - UNIVERSIDADE FEDERAL DO ABC. Resolução do CEC n ${ }^{\circ}$ 7, de 18 de abril de 2017. Define as atividades de extensão universitária da UFABC. Disponível em: http://proec.ufabc.edu.br/images/a-proex/portarias-e-

resolucoes/resolucoes2017/Resolu\%C3\%A7\%C3\%A3o_CEC_007_17_Define_Extens\%C3\% A3o_-_Boletim.pdf. Acesso em: 30 abr. 2020.

UFU - UNIVERSIDADE FEDERAL DE UBERLÂNDIA. Pró-Reitoria de Extensão e Cultura (PROEXC). Programas Institucionais de Extensão. Disponível em: http://www.proexc.ufu.br/programas-institucionais. Acesso em: 30 abr. 2020. 
ULSP - UNIVERSIDADE LIVRE DE SÃO PAULO. Disponível em: http://icaatom.arquivoestado.sp.gov.br/ica-atom/index.php/universidade-livre-de-sao-paulo. Acesso em: 20 mar. 2020.

Submetido em 28 de março de 2020.

Aprovado em 16 de abril de 2020. 